\title{
Using Radar to Advance Migratory Bird Management: An Interagency Collaboration
}

\section{The Need}

Migratory birds face many changes to the landscapes they traverse and the habitats they use. Wind turbines and communications towers, which pose hazards to birds and bats in flight, are being erected across the United States and offshore. Human activities can also destroy or threaten habitats critical to birds during migratory passage, and climate change appears to be altering migratory patterns. The U.S. Fish and Wildlife Service (USFWS) and other agencies are under increasing pressure to identify and evaluate movement patterns and habitats used during migration and other times.

Few tools exist to decipher migratory travels, but radar-based studies of movements and habitat use patterns in songbirds, waterfowl, and bats hold promise. The United States system of more than 150 Doppler weather radars provides continental coverage, similar to the scale of bird migration. Although data stored from weather radar represent perhaps the second largest biological data archive in the world, use of those data is currently limited to technically savvy biologists who can handle the obscure data formats. In addition, complementary mobile radar units and thermal and acoustic monitor- ing can be used in site-specific studies.

Efforts to advance bird conservation and management through the use of radar arose independently in several recent collaborations between U.S. Geological Survey (USGS) and USFWS. This coalition of scientists and managers recently identified the need to work together more closely to foster radar-related research and software development.

\section{The Approach}

U.S. Geological Survey scientists at the Fort Collins Science Center, National Wetlands Research Center, Northern Rocky Mountain Science Center, and Patuxent Wildlife Research Center, as well as USFWS Migratory Bird Program biologists across the country, are collaborating and joining with university partners to develop a suite of products for resource managers. The goals are to identify migratory path-ways and stopover sites for conservation, mitigation, and ecological planning; convey the importance of functional landscapes and unobstructed airspaces for migrating wildlife; enable use of radar by the wider biological, wind power, and related communities; and simplify the analysis of radar data. The long-term focus

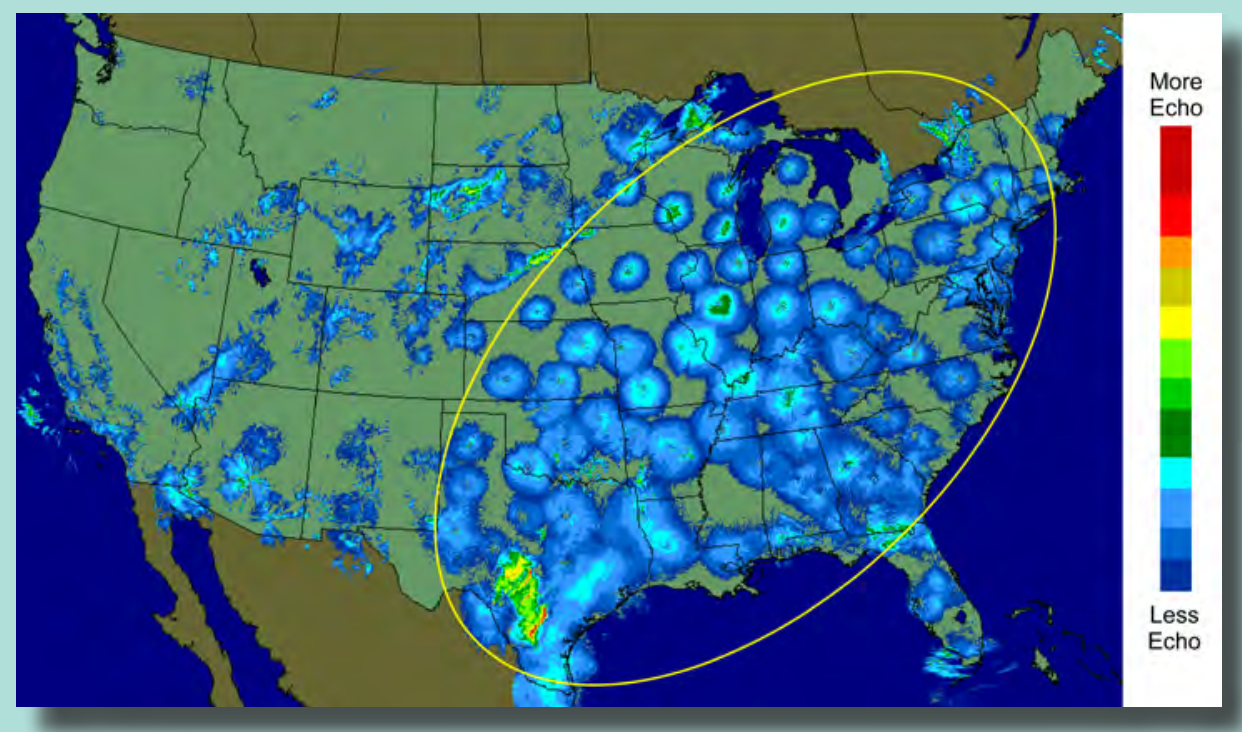

Radar-captured snapshot of spring bird migration across eastern and central United States is to better understand movement patterns and habitat associations of migratory birds and other wildlife. Land managers and industry can use the knowledge and tools developed for migratory bird habitat projects and for optimizing the siting of energy projects and other facilities.

The complementary endeavors, not all of which are funded, concentrate on four fundamentals. One is developing software, in collaboration with National Oceanic and Atmospheric Administration (NOAA) scientists, that enables biologists to access unfiltered weather data and integrate it into geographic information systems. A second is developing artificial intelligence-based filters that separate bird from nonbird radar echoes, with these techniques then being used to map migration patterns. The third is determining characteristics of bird migration in terms of altitude, speed and direction, daily movements, seasonality, and associations with habitats and landforms. The fourth is examining specific movement patterns in relation to towers, wind generation facilities, and tall obstructions.

There are many technical issues that make this work difficult, including complex data structures, massive data sets, digital recognition of birds, large areas not covered by weather radar, and model validation; however, progress will only be furthered by tackling the challenge. The new coalition will meet its goals by (1) facilitating a productive collaboration with NOAA, all Department of the Interior bureaus, state wildlife agencies, universities, power companies, and other partners; (2) building and strengthening the needed scientific capabilities within USGS;

(3) addressing key migratory bird management issues; and (4) ensuring full funding for the collaborative effort.

Suggested citation:

Sojda, R.S., Ruth, J.M., Barrow, W.C., Dawson, D.K., Diehl, R.H., Manville, A., Green, M.T., Krueper, D.J., and Johnston, S., 2005, Using radar to advance migratory bird management: an interagency collaboration: U.S. Geological Survey, Fort Collins Science Center, Fact Sheet 2005-3048, 2 p. 


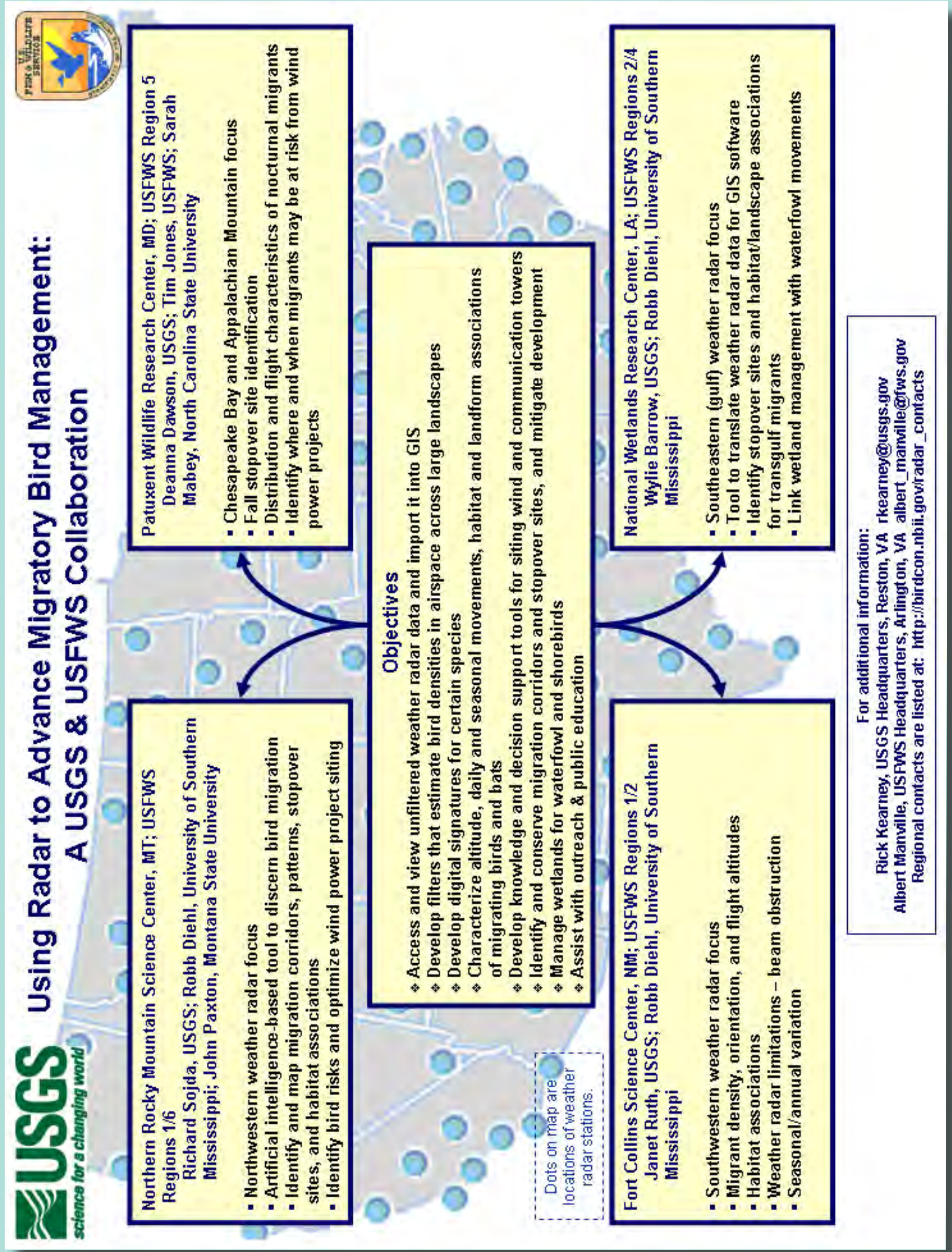

